Utah State University

DigitalCommons@USU

\title{
Is Perfectionism Always Unhealthy? Examining the Moderating Effects of Psychological Flexibility and Self-Compassion
}

Clarissa W. Ong

Utah State University, clarissa.ong@usu.edu

Eric B. Lee

Utah State University, eric.lee@usu.edu

Julie M. Petersen

Utah State University, julie.petersen@aggiemail.usu.edu

Michael E. Levin

Utah State University, michael.levin@usu.edu

Michael P. Twohig

Utah State University, michael.twohig@usu.edu

Follow this and additional works at: https://digitalcommons.usu.edu/psych_stures

Part of the Psychology Commons

\section{Recommended Citation}

Ong, C. W., Lee, E. B., Petersen, J. M., Levin, M. E., \& Twohig, M. P. (in press). Is perfectionism always unhealthy? Examining the moderating effects of psychological flexibility and self-compassion. Journal of Clinical Psychology.

This Article is brought to you for free and open access by the Psychology Student Works at DigitalCommons@USU. It has been accepted for inclusion in Psychology Student Research by an authorized administrator of DigitalCommons@USU. For more information, please contact digitalcommons@usu.edu.

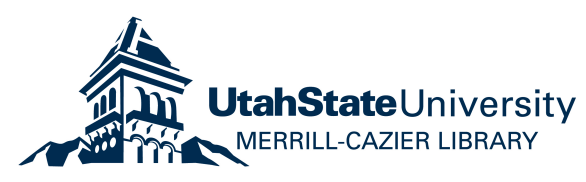


Is Perfectionism Always Unhealthy?

Examining the Moderating Effects of Psychological Flexibility and Self-Compassion 


\begin{abstract}
Objectives: Perfectionism is generally associated with worse mental health outcomes, though evidence suggests elements of it might be helpful. In light of these findings, we examined whether psychological skills like psychological flexibility and self-compassion moderated the relationship between perfectionism and wellbeing (i.e., quality of life, symptom impairment, and psychological distress).
\end{abstract}

Methods: Undergraduate students $(N=677)$ completed self-report measures.

Results: A latent profile analysis identified three perfectionism groups (low, average, high) based on four perfectionism subscales: concern over mistakes, need for approval, rumination, and striving for excellence. Generally, we found that psychological flexibility and/or self-compassion buffered the impact of average and high perfectionism on quality of life and symptom impairment.

Conclusion: Our results support the utility of practicing psychological flexibility and/or selfcompassion for people with average and high levels of perfectionism. Limitations include using a cross-sectional design and non-clinical sample.

Keywords: perfectionism, psychological flexibility, self-compassion, moderation, outcomes, wellbeing 


\section{Is Perfectionism Always Unhealthy?}

Examining the Moderating Effects of Psychological Flexibility and Self-Compassion Perfectionism is defined by the relentless pursuit of high personal standards and selfcriticism when standards are not met. It can be conceptualized as a bifactor model with a general factor of perfectionism and two factors of perfectionistic concerns and perfectionistic striving (Howell et al., 2020; Smith \& Saklofske, 2017). The general factor and perfectionistic concerns are typically associated with poorer outcomes like depression and anxiety, and findings for perfectionistic striving are mixed (Howell et al., 2020; Limburg et al., 2017). For example, one study reported that perfectionistic striving sans concerns was associated with higher levels of subjective happiness and life satisfaction (Suh et al., 2017). These inconsistent findings suggest that there may be moderating variables that alter the relationship between perfectionism and outcomes. Identifying these moderating variables is particularly important given the egosyntonic nature of perfectionism, as people may be more amenable to changing the context in which perfectionism occurs rather than perfectionism per se.

Such a functional approach to treating perfectionism is congruent with empirically supported mindfulness-based psychological interventions like acceptance and commitment therapy (ACT) and compassion-focused therapy (CFT; A-Tjak et al., 2015; Leaviss \& Uttley, 2015). Preliminary data suggest that ACT and CFT may be helpful for treating clinical perfectionism (Matos \& Steindl, 2020; Ong et al., 2019). These therapies emphasize altering responses to thoughts and feelings rather than thoughts and feelings themselves. That is, clients learn to acknowledge perfectionistic standards and self-criticism and respond to them flexibly in ACT or compassionately in CFT. Notably, these therapies do not presume that clients first need to adjust their unrealistic expectations or change their beliefs about their self-worth before they 
can observe improvement in wellbeing. From the perspective of ACT and CFT, the context in which standards and self-criticism occur depends on the skills that are accessible to the person. That is, is self-criticism showing up in a compassionate context wherein the person can recognize the humanity of self-criticism and choose to respond to themselves kindly?

In ACT, the hypothesized process of change is psychological flexibility, the ability to mindfully notice thoughts and feelings in the present moment while consciously selecting behaviors in line with personal values (Hayes et al., 2006). In CFT, the process of change is compassion and self-compassion, which entail developing feelings of warmth, safety, kindness, and support in response to shame and self-criticism (Gilbert, 2009). Both these processes of change are especially relevant to perfectionism given its defining characteristics of rigid adherence to standards and self-criticism in response to perceived failure. Furthermore, both psychological flexibility and self-compassion have been found to moderate the relationship between psychopathology and mental health outcomes, suggesting these skills may have protective effects on well-being by weakening the association between symptoms and outcomes (Ferrari et al., 2018; Gloster et al., 2017). Specifically, psychological flexibility may temper the detrimental effect of perfectionism by encouraging noticing distress and rules without acting on them and facilitating connection with personal values rather than socially prescribed goals. Similarly, self-compassion may be helpful by neutralizing the influence of self-criticism and directing attention toward caring, soothing, and kindness instead.

Given the potential buffering effect of psychological flexibility and self-compassion on perfectionism with respect to wellbeing, we wanted to directly test this hypothesis to clarify the utility of targeting these skills in psychotherapies for perfectionism. Thus, the objective of this study was to test whether psychological flexibility and self-compassion moderate the relationship 
between perfectionism and wellbeing. Given that people may present with higher levels of certain facets of perfectionism than others (e.g., high perfectionistic strivings and low perfectionistic concerns; Suh et al., 2017), we chose to use empirically derived profiles in our moderation analyses to more accurately model the types of perfectionism observed in our sample. We predicted that higher levels of psychological flexibility and self-compassion would attenuate the strength of the relationship between perfectionism and wellbeing, such that participants with high levels of perfectionism would report higher wellbeing if they also reported high psychological flexibility and/or self-compassion.

\section{Method}

\section{Procedure}

Undergraduate students enrolled in psychology classes in the western United States were recruited using a university research participation portal. The same portal assigned course credits to participants who completed the study. Participants signed an informed consent document before anonymously completing study measures on Qualtrics, a secure online data collection platform. Inclusion criteria were (1) at least 18 years old and (2) ability to complete measures in English. The study was approved by the university institutional review board.

\section{Measures}

Perfectionism Inventory (PI; Hill et al., 2004). The PI is a 59-item self-report measure

of perfectionism. The PI comprises eight subscales: (a) concern over mistakes, (b) high standards for others, (c) need for approval, (d) organization, (e) parental pressure, (f) planfulness, (g) rumination, and (h) striving for excellence. Although we administered the full scale, we only used the concern over mistakes, need for approval, rumination, and striving for excellence subscales to identify perfectionism profiles because they are most theoretically relevant to 
maladaptive perfectionism (Shafran et al., 2002). Data from the other subscales (i.e., high standards for others, organization, parental pressure, and planfulness) were not analyzed in this study. Items are rated on a five-point scale from 1 (strongly disagree) to 5 (strongly agree); ratings from each subscale are averaged to produce a subscale score. Items include: "If I make mistakes, people might think less of me" and "I must achieve excellence in everything I do." Higher scores reflect more perfectionism. The PI has demonstrated good psychometric properties (Hill et al., 2004). The four subscales had good internal consistency in our sample ( $\alpha$ s ranged from .81 to .89).

Quality of Life Scale (QOLS; Burckhardt et al., 1989). The QOLS is a 16-item selfreport measure of general functioning and life satisfaction at the time of responding. Respondents rate the extent to which they are satisfied with each listed life domain (e.g., material comfort, health, relationships, employment, recreation) on a seven-point scale from 1 (terrible) to 7 (delighted). Higher scores indicate better quality of life. The QOLS has demonstrated good psychometric properties (Burckhardt et al., 1989). It had excellent internal consistency in the current sample $(\alpha=.90)$.

Outcome Questionnaire-45.2 (OQ-45; Lambert et al., 1996). The OQ-45 is a 45-item self-report measure of symptom severity and functional impairment in the previous week. The OQ-45 has three subscales: (a) symptom distress (i.e., symptoms related to anxiety, affective, and adjustment disorders); (b) interpersonal relations (i.e., loneliness, conflicts with others, dissatisfaction with relationships); and (c) social role (i.e., distress, inefficiency, and difficulties in social roles). Items are rated on a five-point scale from 0 (never) to 4 (almost always); nine items are reverse-scored. Examples include: "I have difficulty concentrating" and "I am satisfied with my relationships with others" (reverse-scored). Higher scores indicate greater symptom 
impairment. The OQ-45 has demonstrated excellent psychometric properties (Lambert et al., 1996). It had excellent internal consistency in our sample $(\alpha=.95)$.

Depression Anxiety Stress Scales (DASS-21; Henry \& Crawford, 2005). The DASS-

21 is a 21-item self-report measure of psychological distress in the areas of depression, anxiety, and stress in the previous week. Each scale consists of seven items that are rated on a four-point scale from 0 (never) to 3 (almost always). Items include: "I found it difficult to relax" and "I felt I wasn't worth much as a person.” Higher scores reflect more distress. The DASS-21 has demonstrated excellent psychometric properties (Henry \& Crawford, 2005). It showed excellent internal consistency in our sample $(\alpha=.94)$.

Comprehensive Assessment of ACT Processes (CompACT; Francis et al., 2016). The CompACT is a 23-item self-report measure of psychological flexibility. It consists of three subscales: (a) openness to experience (i.e., acceptance of internal experiences and detachment from literality); (b) behavioral awareness (i.e., self-awareness and perspective taking); and (c) valued action (i.e., motivation and activation). Items are rated on a seven-point scale from 0 (strongly disagree) to 6 (strongly agree); 12 items are reverse-scored. Examples include: "I act in ways that are consistent with how I wish to live my life" and "I work hard to keep out upsetting feelings" (reverse-scored). Higher scores reflect more psychological flexibility. The CompACT has shown good internal consistency and convergent and divergent validity (Francis et al., 2016). It had good internal consistency in our sample $(\alpha=.85)$.

Self-Compassion Scale (SCS; Neff, 2003). The SCS is a 26-item self-report measure of self-compassion or how someone relates to themselves when distressed. The SCS consists of six subscales: (a) self-kindness; (b) self-judgement; (c) common humanity; (d) isolation; (e) mindfulness, and (f) over-identification. Items are rated on a five-point scale from 1 (almost 
never) to 5 (almost always). Examples include: “I'm disapproving and judgmental about my own flaws and inadequacies" and "I try to see my failings as part of the human condition." Higher scores reflect more self-compassion. The SCS has demonstrated good psychometric properties (Neff, 2003). It showed excellent internal consistency in our sample $(\alpha=.93)$.

\section{Statistical Analyses}

All analyses were conducted with R in RStudio (R Core Team, 2020; RStudio Team, 2020) using the following packages: mclust (Fraley et al., 2012), careless (Yentes \& Wilhelm, 2018), psych (Revelle, 2018), texreg (Leifeld, 2013), and furniture (Barrett \& Brignone, 2017).

Careless or insufficient effort responding. Careless or insufficient effort responding was identified based on response time and long-string analysis (Curran, 2016). Given a recommended cutoff of 2s per item (Huang et al., 2012), we excluded cases that took less than 470s (235 items $\times 2$ s) for completion. In addition, Curran (2016) recommended using a cutoff of at least half the length of the total scale for consecutive responses under the assumption that careless responders may simply select the same answer to every question. Thus, we deleted cases showing the same response for 30 or more consecutive items (our longest scale, the PI, has 59 items and 59/2 = 29.5).

Perfectionistic profiles. A latent profile analysis was used to identify unobserved perfectionism groups in our sample (Fraley \& Raftery, 2002). We used four indicators from the PI: the concern over mistakes, need for approval, rumination, and striving for excellence subscales. Models with mixture components (i.e., profiles) ranging from one to four were sequentially compared until the addition of a mixture component failed to significantly improve fit. As recommended by Nylund et al. (2007), we used both the Bayesian information criterion (BIC) and bootstrap likelihood ratio test (BLRT) to identify the number of latent profiles. The 
BIC is a fit index that allows for model fit comparison across various plausible models; lower absolute BIC values indicate better fitting models. The BLRT uses bootstrapping to estimate the true distribution of the log likelihood difference between the $k-1$ and $k$ class models in order to obtain a $p$-value, which is used to determine if the null $k-1$ class model should be rejected in favor of the alternative $k$ class model (Nylund et al., 2007).

Moderation analyses. A linear regression model was specified for each outcome of interest: quality of life (QOLS), symptom impairment (OQ-45), and psychological distress (DASS-21). Predictors were profile membership (determined from the latent profile analysis), psychological flexibility (CompACT), self-compassion (SCS), and their interaction terms up to a three-way interaction. The average perfectionism group was used as the reference group to which other groups were compared and continuous variables were mean-centered to increase interpretability of findings.

To facilitate interpretation of interaction effects, analyses of variance and Tukey post-hoc tests were used to compare participants across perfectionism profiles and within each perfectionism profile group based on levels of psychological flexibility and self-compassion. For the latter set of comparisons, participants were classified into one of four mutually exclusive "process" subgroups: (1) above average (mean) psychological flexibility and above average selfcompassion, (2) above average psychological flexibility and below average self-compassion, (3) below average psychological flexibility and above average self-compassion, and (4) below average psychological flexibility and below average self-compassion.

\section{Results}

\section{Sample Characteristics}


Data from 34 participants were removed due to faster than expected response times and from four participants who gave the same response consecutively for 30 or more questions. Another 31 records with duplicate IDs and one with incomplete data were also excluded from analyses. Our final sample included 677 participants.

The majority of our college student sample identified as female (69.4\%), European American/White (90.7\%), and members of The Church of Jesus Christ of Latter-day Saints/Mormon (LDS; 80.4\%). The mean sample age was 20.4 years $(S D=4.3)$. Demographic information is presented in Table 1.

\section{Perfectionism Profiles}

BIC values for various covariance matrix structures with between one and seven mixture components indicated the best-fitting model was the VEE (unconstrained residual variance, constrained covariance) with three mixture components. The BLRT was then used to sequentially compare the one- vs. two-profile models, the two- vs. three-profile models, and the three- vs. four-profile models to provide another evaluation of model fit. Significance tests revealed that the two-profile model was significantly different from the one-profile model $(p=$ $.001)$, and that the three-profile model provided a significantly better fit than the two-profile model $(p=.001)$. The three-profile model was not significantly different from the four-class model $(p=.733)$. Thus, we rejected the null two-class model in favor of the alternative threeclass model, whereas we failed to reject the null three-class model in the final comparison. Based on the BIC and BLRT indices, we selected the VEE model with three mixture components as the most parsimonious, best-fitting model (see Table 2).

The perfectionism profiles identified by the latent profile analysis are presented in Figure 1. These groups approximately correspond to presentations along the spectrum of perfectionism, 
which we have labeled: high $(\mathrm{n}=101,14.9 \%)$, average $(\mathrm{n}=444,65.7 \%)$, and low $(\mathrm{n}=131$, 19.4\%). The high perfectionism group showed elevations in concern over mistakes, need for approval, rumination, and striving for excellence compared to other groups. The average perfectionism group had fairly consistent scores across all the PI subscales that fell between those of the high and low perfectionism groups. The low perfectionism group had the lowest scores on the four subscales.

\section{Moderation Effects}

Quality of life (QOLS). The group $\times$ psychological flexibility interaction was significantly associated with quality of life. That is, quality of life depended on both perfectionism group membership and level of psychological flexibility, with psychological flexibility having a protective effect on quality of life (see Figure 2). The total proportion of variance in quality of life explained by this model was $29.2 \%$. Across profiles, self-compassion and psychological flexibility were positively correlated with quality of life (see Figure 2). In addition, the low perfectionism group had the highest mean quality of life, followed by the average perfectionism group, then the high perfectionism group (see Table 4).

Generally, the moderating influence of psychological flexibility was more evident in the average perfectionism and high perfectionism groups. Whereas there were few significant differences between process subgroups for participants with low perfectionism, in the average perfectionism group, participants with below average psychological flexibility and below average self-compassion reported the lowest quality of life. In the high perfectionism group, participants with above average psychological flexibility—regardless of level of selfcompassion — reported higher quality of life than participants with below average psychological flexibility and below average self-compassion (see Table 4). 
Symptom impairment (OQ-45). The three-way interaction of group $\times$ self-compassion $\times$ psychological flexibility was significant, indicating that the effect of group on symptom impairment depended on levels of self-compassion and psychological flexibility (see Table 3). Total proportion of variance in symptom impairment accounted for by the model was $51.3 \%$. The high perfectionism group reported significantly more symptom impairment than the average perfectionism group, which, in turn, reported significantly more symptom impairment than the low perfectionism group (see Table 4). Across profiles, psychological flexibility and selfcompassion were negatively correlated with symptom impairment (see Figure 3).

Based on visual data representation (Figure 3) and means comparisons (Table 4), the three-way interaction appears to be explained by the differential influence of processes in each perfectionism group. Specifically, the processes were associated with more significant differences in the average and high perfectionism groups than the low perfectionism group, such that only participants with above average psychological flexibility and above average selfcompassion reported significantly less symptom impairment in the low perfectionism group, whereas above average psychological flexibility or above average self-compassion was associated with some benefit in the average and high perfectionism groups (see Table 4). Specifically, in the average perfectionism group, reporting above average psychological flexibility, above average self-compassion, or both was linked to less symptom impairment relative to below average psychological flexibility and below average self-compassion. In the high perfectionism group, only groups with above average psychological flexibility—regardless of level of self-compassion-reported less symptom impairment than the group with below average psychological flexibility and below average self-compassion. 
Psychological distress (DASS-21). Only the main effects of group, self-compassion, and psychological flexibility were significantly associated with psychological distress (see Table 3 and Figure 4). The proportion of variance explained by this model was $43.9 \%$. Having high perfectionism (relative to average perfectionism), lower self-compassion, and lower psychological flexibility were independently associated with more psychological distress, and these effects did not depend on the level of other variables.

\section{Discussion}

In this study, we identified latent perfectionism profiles in majority LDS-identified college students and examined the moderating influence of psychological flexibility and selfcompassion on the relationship between perfectionism and wellbeing. The latent profile analysis identified three profiles we labeled low, average, and high perfectionism (see Figure 1). Low perfectionists had consistently low scores for concern over mistakes, need for approval, and rumination even relative to a similar undergraduate sample (Hill et al., 2004); the mean score for striving for excellence was comparable to the aforementioned sample. The low perfectionism profile appears to capture participants who are relatively free from perfectionistic worry and potentially even insensitive to errors and social feedback (nonperfectionists). The average perfectionists showed consistent scores across the domains of concern over mistakes, need for approval, rumination, and striving for excellence. In addition, given the majority of our sample $(65.7 \%)$ fit this profile, it seems this group describes participants who are approximately as concerned about making mistakes and doing well as most others. The high perfectionism profile was characterized by high levels of distress in response to mistakes, sensitivity to criticism, worry about past, present, and future failure, and personal standards, which is the perfectionistic profile commonly correlated with worse mental health outcomes (Limburg et al., 2017). 
Partially in line with our prediction, the relationship between high perfectionism and worse outcomes was attenuated in the context of above average psychological flexibility and/or above average self-compassion for quality of life and symptom impairment. Average and high perfectionism was associated with better quality of life and less symptom impairment when psychological flexibility was above average — regardless of level of self-compassion—compared to when levels of psychological flexibility and self-compassion were below average. Above average self-compassion alone appeared to confer some protective effect on quality of life and symptom impairment relative to below average self-compassion in the average perfectionism group but not in the high perfectionism group. Furthermore, reporting above average psychological flexibility was associated with better outcomes in the average and high perfectionism groups — regardless of level of self-compassion — relative to reporting below average psychological flexibility and below average self-compassion.

In general, psychological flexibility and self-compassion did not show much influence in the low perfectionism group wherein most participants reported relatively high levels of functioning. In contrast, participants with average perfectionism reported worse outcomes in the context of below average psychological flexibility and below average self-compassion. In addition, there were few differences among participants with average or high perfectionism who reported above average psychological flexibility - regardless of level of self-compassion. These findings suggest that practicing psychological flexibility may be especially important for people with higher levels of perfectionism, whereas practicing either psychological flexibility or selfcompassion may be equivalently helpful for people with average perfectionism. We did not find a synergistic effect of psychological flexibility and self-compassion except on symptom impairment in the low perfectionism group (although mean scores were consistently high in this 
group anyway). Our results also indicate that people with low perfectionism may be able to maintain relatively high levels of functioning even with below average psychological flexibility and below average self-compassion.

We did not observe any significant interactions of psychological flexibility and selfcompassion on psychological distress_contradicting our prediction. This could be because distress is more like a symptom than an effect of symptoms, whereas quality of life and symptom impairment are associated with the impact of symptoms. As such, distress might be more closely tied to perfectionistic presentations and reflect the negative affect implicated in high standards and self-criticism. Yet, the skills of psychological flexibility and self-compassion posit that it is possible to live a meaningful life in the presence of distress, depending on how we respond to it. In other words, practicing psychological flexibility and self-compassion may not immediately decrease distress but instead work through decreasing the effect of perfectionistic distress on wellbeing and functioning.

Overall, our results suggest that practicing self-compassion and/or psychological flexibility may temper the relationship between perfectionism and outcomes. Specifically, these skills appear to be beneficial for quality of life and symptom impairment when perfectionism is average or high. This could be because, in the context of psychological flexibility, distress, sensitivity to criticism, and worry are observed with dispassionate curiosity rather than treated as problems that need to be solved. Similarly, in the context of self-compassion, these inner experiences are recognized as normative reactions to societal expectations to be successful and common to the human experience. Therefore, perfectionists who practice psychological flexibility or self-compassion may be better able to show themselves empathy without judgment 
in the face of failure, use these emotional data to clarify their values, and constructively channel their energy toward their goals.

Given that the skills of psychological flexibility and self-compassion are theoretically expected to have a greater positive effect when distress is higher, it may be unsurprising that these effects were more prominent in the average and high perfectionism groups. Moreover, the independent influence of above average psychological flexibility was more consistent across profiles and outcomes than that of above average self-compassion. This could be because, in some ways, self-compassion is entailed in psychological flexibility. That is, being willing to be open to experiences and recognizing that the self is more than pain and self-critical thoughts is an inherently self-compassionate stance.

\section{Limitations}

First, because of the cross-sectional design, we could not establish causal relationships. For example, it is possible that better wellbeing improved self-compassion and psychological flexibility among high perfectionists in our sample. However, given evidence supporting selfcompassion and psychological flexibility as processes of change (Hayes et al., 2006; MacBeth \& Gumley, 2012), the more plausible interpretation is that the relationship is at least bidirectional. Second, evidence suggests that for certain measures of psychological flexibility, low scores may be better conceptualized as a distinct construct of psychological inflexibility with its own performance characteristics (Rolffs et al., 2016). This possibility has not been examined for the CompACT, though if found to be applicable to the CompACT, we might better conceptualize the protective element in our results being practicing psychological flexibility as opposed to reducing psychological inflexibility. Third, the latent variable approach precluded examination of subscales of perfectionism (e.g., concern over mistakes), which would have provided a more 
fine-grained picture of current analyses. However, given our research question and interest in intra-individual perfectionistic presentations, we opted to use empirically derived latent profiles for a more holistic representation of the relationship between perfectionism and putative protective factors. This approach had the additional benefit of producing more easily interpretable and clinically useful moderation analyses. At the same time, there is information to be gained by examining specific perfectionism subscales in the context of self-compassion and psychological flexibility and this should be considered in future research. Finally, our sample was non-clinical and homogeneous (i.e., college students, most identified as White and LDS). In particular, the lack of diversity could have limited generalizability of our findings as beliefs specific to the LDS religion may have influenced the presentation of perfectionism in our sample (Allen \& Wang, 2014). For example, LDS religiosity is associated with greater levels of selforiented perfection which places emphasis on high self-prescribed standards over externallyprescribed standards (Peer \& McGraw, 2017). It is therefore possible that present findings will be less relevant to people for whom perfectionism is more ego-dystonic. Replication of our findings in other populations with more diversity and in clinical samples is needed to determine if the protective influence of self-compassion and psychological flexibility is robust across demographic characteristics and clinical severity. 


\section{Declaration of Interest Statement}

The authors report no conflict of interest. 


\section{References}

A-Tjak, J. G. L., Davis, M. L., Morina, N., Powers, M. B., Smits, J. A., \& Emmelkamp, P. M. (2015). A meta-analysis of the efficacy of acceptance and commitment therapy for clinically relevant mental and physical health problems. Psychotherapy and Psychosomatics, 84(1), 30-36. https://doi.org/10.1159/000365764

Allen, G. E. K., \& Wang, K. T. (2014). Examining religious commitment, perfectionism, scrupulosity, and well-being among LDS individuals. Psychology of Religion and Spirituality, 6(3), 257-264. https://doi.org/10.1037/a0035197

Barrett, T. S., \& Brignone, E. (2017). Furniture for quantitative scientists. $R$ Journal, 9, 142-148.

Burckhardt, C. S., Woods, S. L., Schultz, A. A., \& Ziebarth, D. M. (1989). Quality of life of adults with chronic illness: A psychometric study. Research in Nursing \& Health, 12(6), 347-354. https://doi.org/10.1002/nur.4770120604

Curran, P. G. (2016). Methods for the detection of carelessly invalid responses in survey data. Journal of Experimental Social Psychology, 66, 4-19. https://doi.org/10.1016/j.jesp.2015.07.006

Ferrari, M., Yap, K., Scott, N., Einstein, D. A., \& Ciarrochi, J. (2018). Self-compassion moderates the perfectionism and depression link in both adolescence and adulthood. PLoS One, 13(2), e0192022. https://doi.org/10.1371/journal.pone.0192022

Fraley, C., \& Raftery, A. E. (2002). Model-based Clustering, Discriminant Analysis and Density Estimation. Journal of the American Statistical Association, 97, 611-631.

Fraley, C., Raftery, A. E., Murphy, T. B., \& Scrucca, L. (2012). mclust Version 4 for R: Normal Mixture Modeling for Model-Based Clustering, Classification, and Density Estimation Technical Report No. 597.

Francis, A. W., Dawson, D. L., \& Golijani-Moghaddam, N. (2016). The development and validation of the Comprehensive assessment of Acceptance and Commitment Therapy processes (CompACT). Journal of Contextual Behavioral Science, 5(3), 134-145.

Gilbert, P. (2009). Introducing compassion-focused therapy. Advances in psychiatric treatment, 15(3), 199.

Gloster, A. T., Meyer, A. H., \& Lieb, R. (2017). Psychological flexibility as a malleable public health target: Evidence from a representative sample. Journal of Contextual Behavioral Science, 6(2), 166-171. https://doi.org/10.1016/j.jcbs.2017.02.003

Hayes, S. C., Luoma, J. B., Bond, F. W., Masuda, A., \& Lillis, J. (2006). Acceptance and commitment therapy: Model, processes and outcomes. Behaviour Research and Therapy, 44(1), 1-25. https://doi.org/10.1016/j.brat.2005.06.006 
Henry, J. D., \& Crawford, J. R. (2005, Jun). The short-form version of the Depression Anxiety Stress Scales (DASS-21): construct validity and normative data in a large non-clinical sample. British Journal of Clinical Psychology, 44(Pt 2), 227-239. https://doi.org/10.1348/014466505X29657

Hill, R. W., Huelsman, T. J., Furr, R. M., Kibler, J., Vicente, B. B., \& Kennedy, C. (2004). A new measure of perfectionism: The Perfectionism Inventory. Journal of personality assessment, 82(1), 80-91.

Howell, J., Anderson, R., Egan, S., \& McEvoy, P. (2020, Jul 28). One factor? Two factor? Bifactor? A psychometric evaluation of the Frost Multidimensional Scale and the Clinical Perfectionism Questionnaire. Cognitive Behaviour Therapy, 1-13. https://doi.org/10.1080/16506073.2020.1790645

Huang, J. L., Curran, P. G., Keeney, J., Poposki, E. M., \& DeShon, R. P. (2012). Detecting and deterring insufficient effort responding to surveys. Journal of Business and Psychology, 27(1), 99-114. https://doi.org/10.1007/s10869-011-9231-8

Lambert, M. J., Burlingame, G. M., Umphress, V., Hansen, N. B., Vermeersch, D. A., Clouse, G. C., \& Yanchar, S. C. (1996). The reliability and validity of the Outcome Questionnaire. Clinical Psychology \& Psychotherapy, 3(4), 249-258. https://doi.org/10.1002/(SICI)1099-0879(199612)3:4<249::AID-CPP106>3.0.CO;2-S

Leaviss, J., \& Uttley, L. (2015, Apr). Psychotherapeutic benefits of compassion-focused therapy: An early systematic review. Psychological medicine, 45(5), 927-945. https://doi.org/10.1017/s0033291714002141

Leifeld, P. (2013). texreg: Conversion of statistical model output in R to LaTeX and HTML tables. Journal of Statistical Software, 55(8), 1-24. https://doi.org/10.18637/jss.v055.i08

Limburg, K., Watson, H. J., Hagger, M. S., \& Egan, S. J. (2017). The relationship between perfectionism and psychopathology: A meta-analysis. Journal of Clinical Psychology, 73(10), 1301-1326. https://doi.org/10.1002/jclp.22435

MacBeth, A., \& Gumley, A. (2012, Aug). Exploring compassion: A meta-analysis of the association between self-compassion and psychopathology. Clinical Psychology Review, 32(6), 545-552. https://doi.org/10.1016/j.cpr.2012.06.003

Matos, M., \& Steindl, S. R. (2020). "You are already all you need to be": A case illustration of compassion-focused therapy for shame and perfectionism. Journal of Clinical Psychology, 76(11), 2079-2096. https://doi.org/10.1002/jclp.23055

Neff, K. D. (2003). The development and validation of a scale to measure self-compassion. Self and identity, 2(3), 223-250. 
Nylund, K. L., Asparouhov, T., \& Muthén, B. O. (2007). Deciding on the Number of Classes in Latent Class Analysis and Growth Mixture Modeling: A Monte Carlo Simulation Study. Structural Equation Modeling, 14(4), 535-569. https://doi.org/10.1080/10705510701575396

Ong, C. W., Lee, E. B., Krafft, J., Terry, C. L., Barrett, T. S., Levin, M. E., \& Twohig, M. P. (2019). A randomized controlled trial of acceptance and commitment therapy for clinical perfectionism. Journal of Obsessive-Compulsive and Related Disorders, 22. https://doi.org/10.1016/j.jocrd.2019.100444

Peer, S. O., \& McGraw, J. S. (2017). Mixed-method study of perfectionism and religiosity among Mormons: Implications for cultural competence and clinical practice. Issues in Religion and Psychotherapy, 38(1), 12.

R Core Team. (2020). R: A language and environment for statistical computing. R Foundation for Statistical Computing. https://www.R-project.org/

Revelle, W. (2018). psych: Procedures for psychological, psychometric, and personality research. $R$ package version 1.8.10. https://CRAN.R-project.org/package=psych

Rolffs, J. L., Rogge, R. D., \& Wilson, K. G. (2016). Disentangling components of flexibility via the hexaflex model: Development and validation of the Multidimensional Psychological Flexibility Inventory (MPFI). Assessment, 25(4), 458-482. https://doi.org/10.1177/1073191116645905

RStudio Team. (2020). RStudio: Integrated Development for R. RStudio, Inc. http://www.rstudio.com/

Shafran, R., Cooper, Z., \& Fairburn, C. G. (2002). Clinical perfectionism: A cognitivebehavioural analysis. Behaviour Research and Therapy, 40(7), 773-791. https://doi.org/10.1016/S0005-7967(01)00059-6

Smith, M. M., \& Saklofske, D. H. (2017, May-Jun). The structure of multidimensional perfectionism: Support for a bifactor model With a dominant general factor. Journal of Personality Assessment, 99(3), 297-303. https://doi.org/10.1080/00223891.2016.1208209

Suh, H., Gnilka, P. B., \& Rice, K. G. (2017). Perfectionism and well-being: A positive psychology framework. Personality and Individual Differences, 111, 25-30. https://doi.org/10.1016/j.paid.2017.01.041

Yentes, R. D., \& Wilhelm, F. (2018). careless: Procedures for computing indices of careless responding. $R$ package version 1.1.3. 
Table 1

Sample Descriptives

\begin{tabular}{ll}
\hline & $\begin{array}{l}\text { Mean/Count } \\
(\text { SD/\%) }\end{array}$ \\
\hline Age & $20.4(4.3)$ \\
Gender identity & $470(69.4 \%)$ \\
Female & $207(30.6 \%)$ \\
Male & \\
Ethnic identity & $3(0.4 \%)$ \\
Native American/Indigenous & $3(0.4 \%)$ \\
Asian & $3(0.4 \%)$ \\
Black & $20(3 \%)$ \\
Latinx & $2(0.3 \%)$ \\
Pacific Islander & $614(90.7 \%)$ \\
White & $32(4.7 \%)$ \\
Multiracial & \\
Religion & $544(80.4 \%)$ \\
The Church of Jesus Christ of Latter-day Saints/Mormon & $20(3 \%)$ \\
Catholic & $2(0.3 \%)$ \\
Methodist & $4(0.6 \%)$ \\
Protestant & $3(0.4 \%)$ \\
Lutheran & $2(0.3 \%)$ \\
Buddhist & $78(11.5 \%)$ \\
Not religious & $24(3.5 \%)$ \\
Not listed &
\end{tabular}


Table 2

Fit Indices from Latent Profile Analysis for One- to Four-Profile Models

\begin{tabular}{|c|c|c|c|c|c|c|c|c|c|c|}
\hline Model & Profile & Count & $\begin{array}{l}\text { Probability } \\
\text { of profile } \\
\text { membership }\end{array}$ & $\mathrm{BIC}$ & $\mathrm{BLRT}^{\mathrm{a}}$ & $p^{\mathrm{a}}$ & $\begin{array}{l}\text { Concern } \\
\text { over } \\
\text { mistakes } \\
\end{array}$ & $\begin{array}{l}\text { Need for } \\
\text { approval }\end{array}$ & Rumination & $\begin{array}{l}\text { Striving } \\
\text { for } \\
\text { excellence }\end{array}$ \\
\hline One-profile & & & & -5130.262 & & & 3.122969 & 3.510340 & 3.424984 & 3.513786 \\
\hline \multirow[t]{2}{*}{ Two-profile } & 1 & 427 & 0.624 & -5108.757 & 54.444 & .001 & 3.465366 & 4.026703 & 3.715051 & 3.630064 \\
\hline & 2 & 250 & 0.376 & & & & 2.553730 & 2.651881 & 2.942746 & 3.320474 \\
\hline \multirow[t]{3}{*}{ Three-profile } & 1 & 446 & 0.653 & -5078.537 & 75.494 & .001 & 3.138320 & 3.609385 & 3.502430 & 3.481094 \\
\hline & 2 & 99 & 0.150 & & & & 4.397788 & 4.546423 & 4.479438 & 4.161584 \\
\hline & 3 & 132 & 0.197 & & & & 2.104552 & 2.395671 & 2.367973 & 3.130511 \\
\hline \multirow[t]{4}{*}{ Four-profile } & 1 & 21 & 0.091 & -5112.698 & 4.946 & .705 & 3.570757 & 3.614872 & 3.372251 & 3.332929 \\
\hline & 2 & 413 & 0.557 & & & & 3.051923 & 3.592483 & 3.513727 & 3.498490 \\
\hline & 3 & 110 & 0.158 & & & & 4.389674 & 4.526846 & 4.460854 & 4.138694 \\
\hline & 4 & 133 & 0.194 & & & & 2.087010 & 2.399807 & 2.353445 & 3.134260 \\
\hline
\end{tabular}

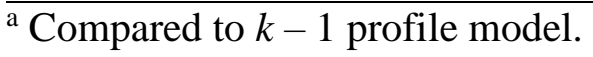

Note. BLRT results compared VEE models across the range of mixture components, whereas other values correspond to the bestfitting model for the specified number of clusters based on the BIC. BIC = Bayesian information criterion; BLRT = bootstrap likelihood ratio test. 
Table 3

Regression Coefficients and Standard Errors for Outcomes of Interest

\begin{tabular}{|c|c|c|c|}
\hline & QOLS & OQ-45 & DASS-21 \\
\hline Group: High perfectionism ${ }^{\mathrm{a}}$ & $1.39(2.34)$ & $6.89(3.57)^{\dagger}$ & $6.18 * *(1.92)$ \\
\hline Group: Low perfectionism ${ }^{a}$ & $1.73(1.94)$ & $-0.64(2.97)$ & $-2.02(1.60)$ \\
\hline SCS & $6.01 * * *(1.17)$ & $-10.92 * * *(1.77)$ & $-4.53 * * *(0.96)$ \\
\hline CompACT & $0.22 * * *(0.04)$ & $-0.61 * * *(0.06)$ & $-0.29 * * *(0.03)$ \\
\hline Group: High perfectionism $\times$ SCS & $-1.16(3.15)$ & $-1.55(4.78)$ & $-1.85(2.58)$ \\
\hline Group: Low perfectionism $\times$ SCS & $-2.45(3.31)$ & $-6.46(5.01)$ & $-0.74(2.72)$ \\
\hline Group: High perfectionism $\times$ CompACT & $0.40 * *(0.14)$ & $-0.37(0.21)^{\dagger}$ & $0.01(0.12)$ \\
\hline Group: Low perfectionism $\times$ CompACT & $-0.15(0.13)$ & $-0.17(0.21)$ & $-0.02(0.11)$ \\
\hline $\mathrm{SCS} \times \mathrm{CompACT}$ & $-0.16 * *(0.06)$ & $0.29 * *(0.09)$ & $0.07(0.05)$ \\
\hline Group: High perfectionism $\times$ SCS $\times$ CompACT & $0.24(0.14)$ & $-0.45 *(0.21)$ & $-0.03(0.12)$ \\
\hline Group: Low perfectionism $\times$ SCS $\times$ CompACT & $0.26(0.17)$ & $0.24(0.26)$ & $0.13(0.14)$ \\
\hline $\mathrm{R}^{2}$ & 0.301 & 0.521 & 0.448 \\
\hline Adjusted $\mathrm{R}^{2}$ & 0.290 & 0.513 & 0.439 \\
\hline Number of observations & 675 & 663 & 674 \\
\hline RMSE & 11.99 & 18.00 & 9.84 \\
\hline
\end{tabular}

$* p<.05 . * * p<.01 . * * * p<.001$.

${ }^{a}$ Reference group is average perfectionism.

Note. Continuous variables were mean-centered. QOLS = Quality of Life Scale; OQ-45 = Outcome Questionnaire-45; DASS-21 = Depression Anxiety Stress Scales; SCS = Self-Compassion Scale; CompACT = Comprehensive Assessment of ACT Processes . 
Table 4

Means and Standard Deviations in Each Perfectionism Group by Level of Psychological Flexibility and Self-Compassion

\begin{tabular}{|c|c|c|c|c|c|c|c|c|c|c|c|c|c|c|c|}
\hline & \multicolumn{5}{|c|}{ Low Perfectionism } & \multicolumn{5}{|c|}{ Average Perfectionism } & \multicolumn{5}{|c|}{ High Perfectionism } \\
\hline & $\begin{array}{l}\text { All } \\
(n= \\
132)\end{array}$ & $\begin{array}{l}\text { Below } \\
\text { mean } \\
\mathrm{PF} \text { and } \\
\mathrm{SC}(n= \\
8)\end{array}$ & $\begin{array}{l}\text { Above } \\
\text { mean } \\
\text { PF } \\
(n=6)\end{array}$ & $\begin{array}{l}\text { Above } \\
\text { mean } \\
\mathrm{SC} \\
(n=19)\end{array}$ & $\begin{array}{l}\text { Above } \\
\text { mean } \\
\text { PF and } \\
\text { SC } \\
(n=98)\end{array}$ & $\begin{array}{l}\text { All } \\
(n= \\
446)\end{array}$ & $\begin{array}{l}\text { Below } \\
\text { mean } \\
\mathrm{PF} \text { and } \\
\mathrm{SC}(n= \\
158)\end{array}$ & $\begin{array}{l}\text { Above } \\
\text { mean } \\
\text { PF } \\
(n=65)\end{array}$ & $\begin{array}{l}\text { Above } \\
\text { mean } \\
\mathrm{SC} \\
(n=88)\end{array}$ & $\begin{array}{l}\text { Above } \\
\text { mean } \\
\mathrm{PF} \text { and } \\
\mathrm{SC} \\
(n= \\
134)\end{array}$ & $\begin{array}{l}\text { All } \\
(n=99)\end{array}$ & $\begin{array}{l}\text { Below } \\
\text { mean } \\
\mathrm{PF} \text { and } \\
\mathrm{SC}(n= \\
75)\end{array}$ & $\begin{array}{l}\text { Above } \\
\text { mean } \\
\text { PF } \\
(n=13)\end{array}$ & $\begin{array}{l}\text { Above } \\
\text { mean } \\
\mathrm{SC} \\
(n=7)\end{array}$ & $\begin{array}{l}\text { Above } \\
\text { mean } \\
\text { PF and } \\
\text { SC } \\
(n=4)\end{array}$ \\
\hline QOLS & $\begin{array}{l}93.3^{\mathrm{A}} \\
(10.6)\end{array}$ & $\begin{array}{l}93.4^{\mathrm{a}} \\
(9.10)\end{array}$ & $\begin{array}{l}83.3^{a, b} \\
(10.3)\end{array}$ & $\begin{array}{l}88.1^{\mathrm{a}, \mathrm{b}} \\
(14.0)\end{array}$ & $\begin{array}{l}94.9^{\mathrm{a}, \mathrm{c}} \\
(9.46)\end{array}$ & $\begin{array}{l}86.4^{\mathrm{B}} \\
(13.7)\end{array}$ & $\begin{array}{l}79.9^{a} \\
(13.6)\end{array}$ & $\begin{array}{l}87.0^{\mathrm{b}} \\
(13.4)\end{array}$ & $\begin{array}{l}89.8^{\mathrm{b}} \\
(12.8)\end{array}$ & $\begin{array}{l}91.6^{b} \\
(11.3)\end{array}$ & $\begin{array}{l}77.2^{\mathrm{C}} \\
(15.8)\end{array}$ & $\begin{array}{l}73.2^{\mathrm{a}} \\
(13.7)\end{array}$ & $\begin{array}{l}90.0^{c} \\
(14.1)\end{array}$ & $\begin{array}{l}85.6^{\mathrm{a}, \mathrm{c}} \\
(20.3)\end{array}$ & $\begin{array}{l}97.8^{\mathrm{b}, \mathrm{c}} \\
(5.85)\end{array}$ \\
\hline OQ-45 & $\begin{array}{l}39.1^{\mathrm{A}} \\
(20.0)\end{array}$ & $\begin{array}{l}60.0^{\mathrm{a}} \\
(13.1)\end{array}$ & $\begin{array}{l}42.7^{\mathrm{a}, \mathrm{b}} \\
(24.3)\end{array}$ & $\begin{array}{l}51.2^{\mathrm{a}} \\
(31.6)\end{array}$ & $\begin{array}{l}34.9^{\mathrm{b}} \\
(14.9)\end{array}$ & $\begin{array}{l}56.5^{\mathrm{B}} \\
(22.6)\end{array}$ & $\begin{array}{l}71.1^{\mathrm{a}} \\
(20.2)\end{array}$ & $\begin{array}{l}50.6^{\mathrm{b}, \mathrm{c}} \\
(19.7)\end{array}$ & $\begin{array}{l}55.3^{\mathrm{b}} \\
(19.9)\end{array}$ & $\begin{array}{l}43.0^{c} \\
(18.0)\end{array}$ & $\begin{array}{l}82.6^{\mathrm{C}} \\
(25.4)\end{array}$ & $\begin{array}{l}89.0^{\mathrm{a}} \\
(21.8)\end{array}$ & $\begin{array}{l}58.9^{\mathrm{b}} \\
(16.6)\end{array}$ & $\begin{array}{l}76.8^{a, b} \\
(41.1)\end{array}$ & $\begin{array}{l}49.0^{\mathrm{b}, \mathrm{c}} \\
(12.0)\end{array}$ \\
\hline $\begin{array}{l}\text { DASS- } \\
21\end{array}$ & $\begin{array}{l}9.98^{\mathrm{A}} \\
(9.09) \\
\end{array}$ & $\begin{array}{l}15.4^{\mathrm{a}} \\
(7.95) \\
\end{array}$ & $\begin{array}{l}9.83^{\mathrm{a}} \\
(4.22) \\
\end{array}$ & $\begin{array}{l}15.2^{\mathrm{a}, \mathrm{b}} \\
(15.0)\end{array}$ & $\begin{array}{l}8.53^{\mathrm{a}, \mathrm{c}} \\
(7.34) \\
\end{array}$ & $\begin{array}{l}17.6^{\mathrm{B}} \\
(11.3) \\
\end{array}$ & $\begin{array}{l}24.1^{\mathrm{a}} \\
(11.6)\end{array}$ & $\begin{array}{l}14.8^{\mathrm{b}, \mathrm{c}} \\
(8.40)\end{array}$ & $\begin{array}{l}17.8^{\mathrm{b}} \\
(11.2) \\
\end{array}$ & $\begin{array}{l}11.3^{c} \\
(7.69)\end{array}$ & $\begin{array}{l}32.3^{\mathrm{C}} \\
(14.4) \\
\end{array}$ & $\begin{array}{l}35.6^{\mathrm{a}} \\
(12.6) \\
\end{array}$ & $\begin{array}{l}22.4^{\mathrm{b}, \mathrm{c}} \\
(13.0)\end{array}$ & $\begin{array}{l}22.0^{\mathrm{a}, \mathrm{c}} \\
(21.4)\end{array}$ & $\begin{array}{l}19.5^{\mathrm{a}, \mathrm{c}} \\
(8.81)\end{array}$ \\
\hline
\end{tabular}

Note. Superscript letters represent significant differences at $p<.05$ in post-hoc multiple comparison analyses; uppercase letters indicate comparisons between perfectionism profiles and lowercase letters indicate comparisons within profiles. QOLS = Quality of Life Scale; OQ-45 = Outcome Questionnaire-45; DASS-21 = Depression Anxiety Stress Scales; PF = psychological flexibility as measured by the CompACT [Comprehensive Assessment of ACT Processes]; SC = self-compassion as measured by the SCS [SelfCompassion Scale]. 


\section{Figures}

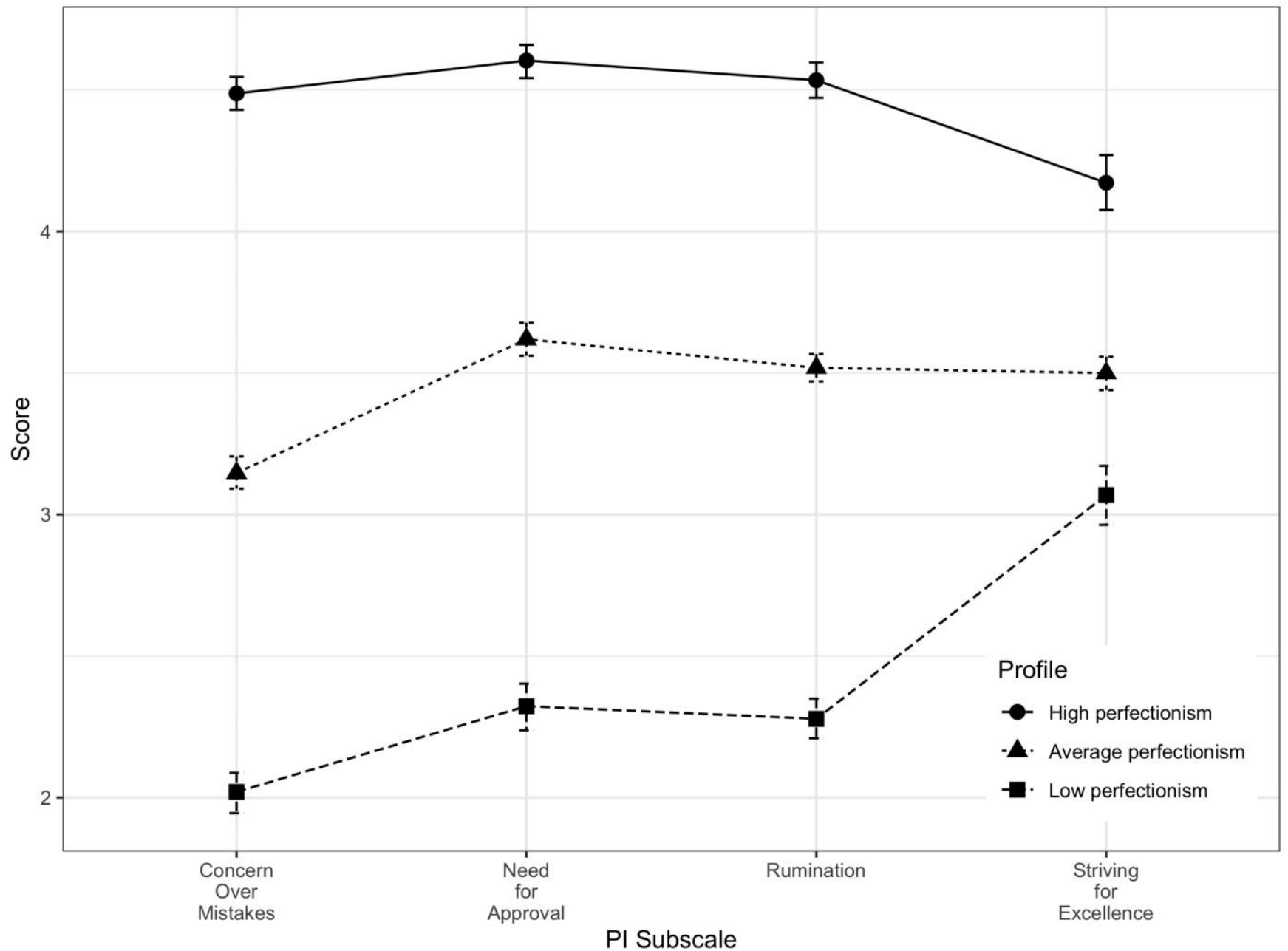

Figure 1. Plot of means for Perfectionism Inventory (PI) subscales showing three individual-level profiles of perfectionism identified using latent profile analysis: high perfectionism, average perfectionism, and low perfectionism. 


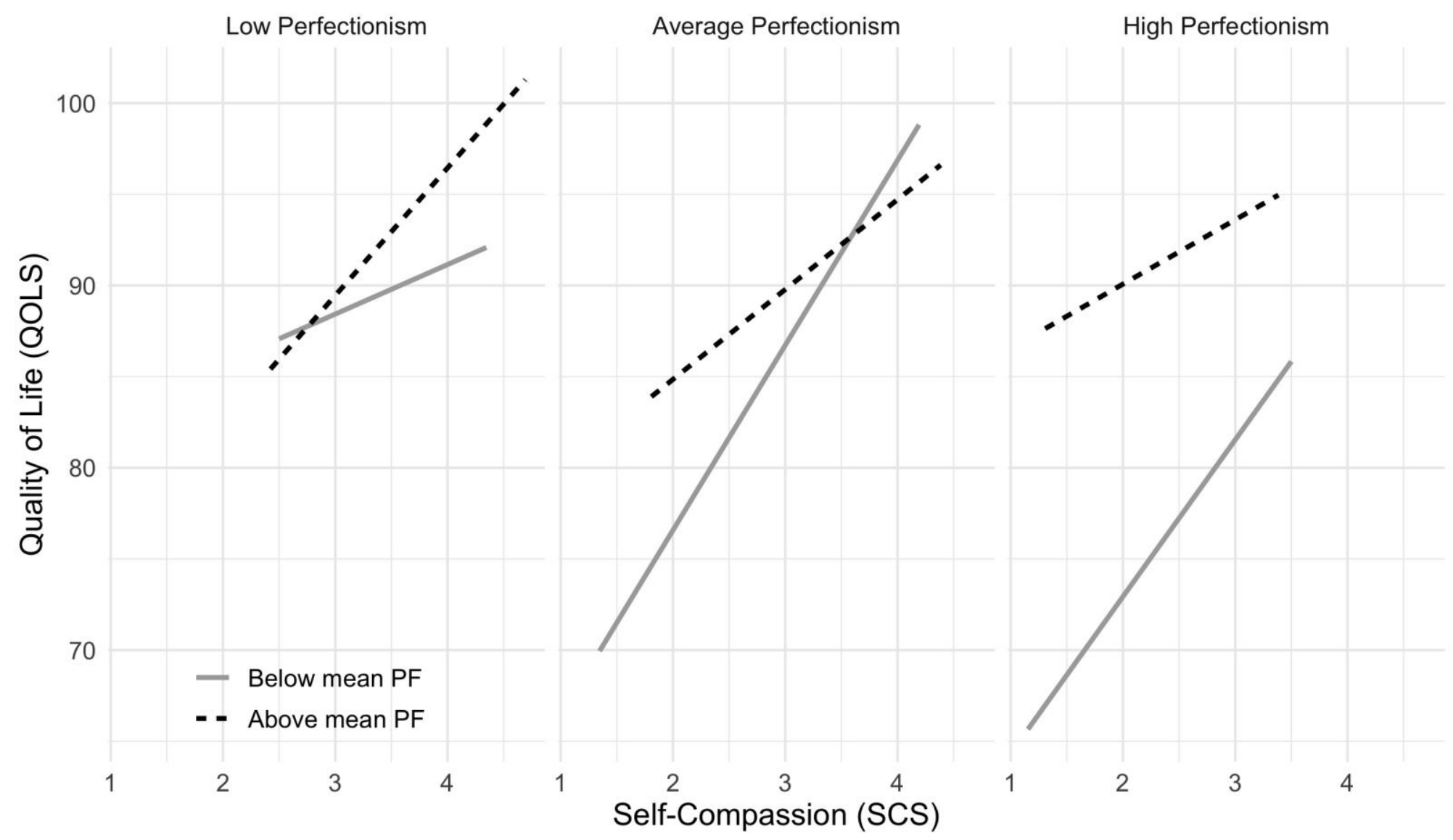

Figure 2. Plot of best-fitting lines showing the non-significant three-way interaction effect of group, self-compassion, and psychological flexibility on quality of life. QOLS = Quality of Life Scale; PF = psychological flexibility (as measured by the CompACT [Comprehensive Assessment of ACT Processes]); SCS = Self-Compassion Scale. 


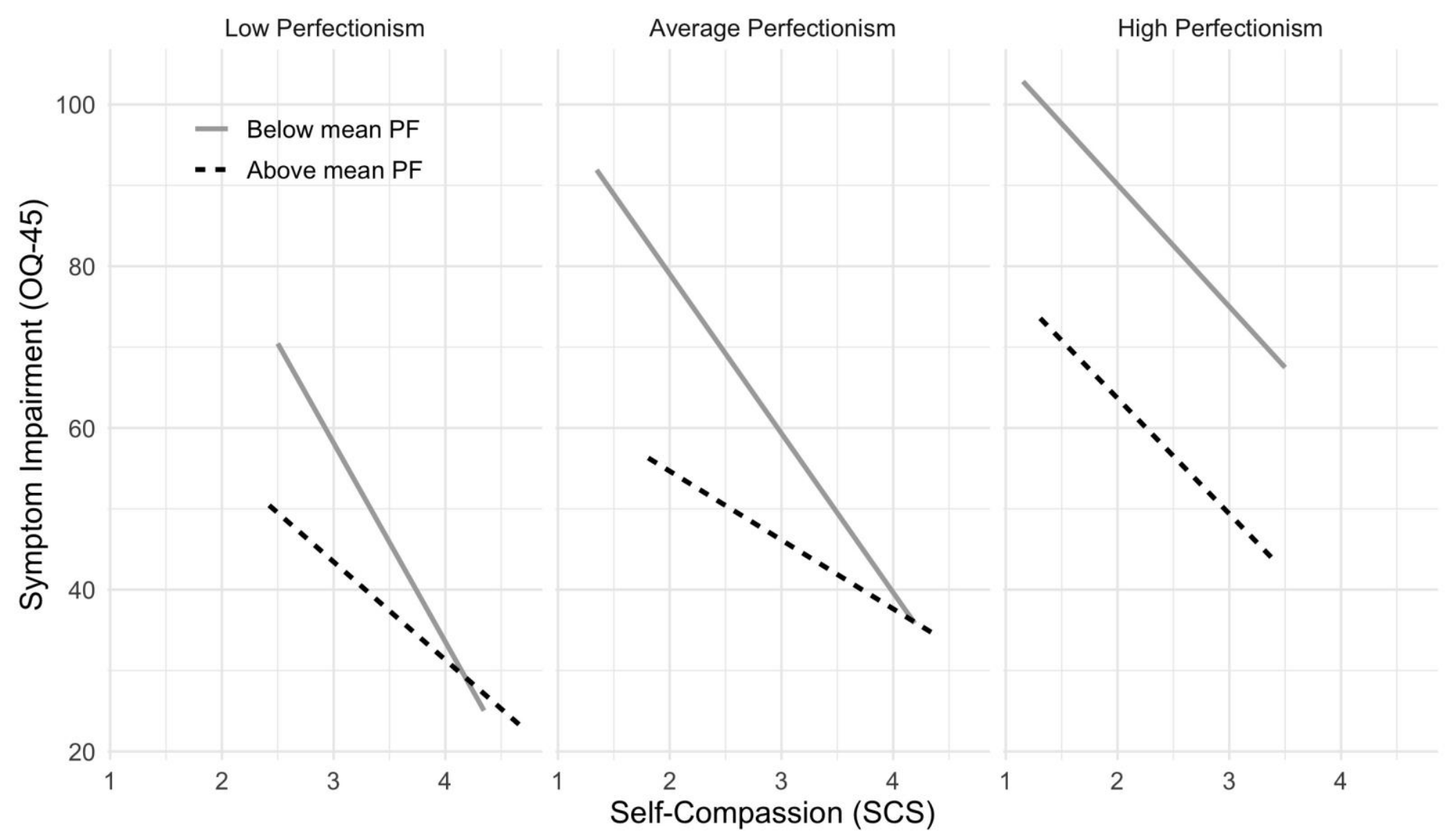

Figure 3. Plot of best-fitting lines showing the three-way interaction effect of group, self-compassion, and psychological flexibility on symptom impairment. OQ-45 = Outcome Questionnaire-45; PF = psychological flexibility (as measured by the CompACT [Comprehensive Assessment of ACT Processes]); SCS = Self-Compassion Scale. 


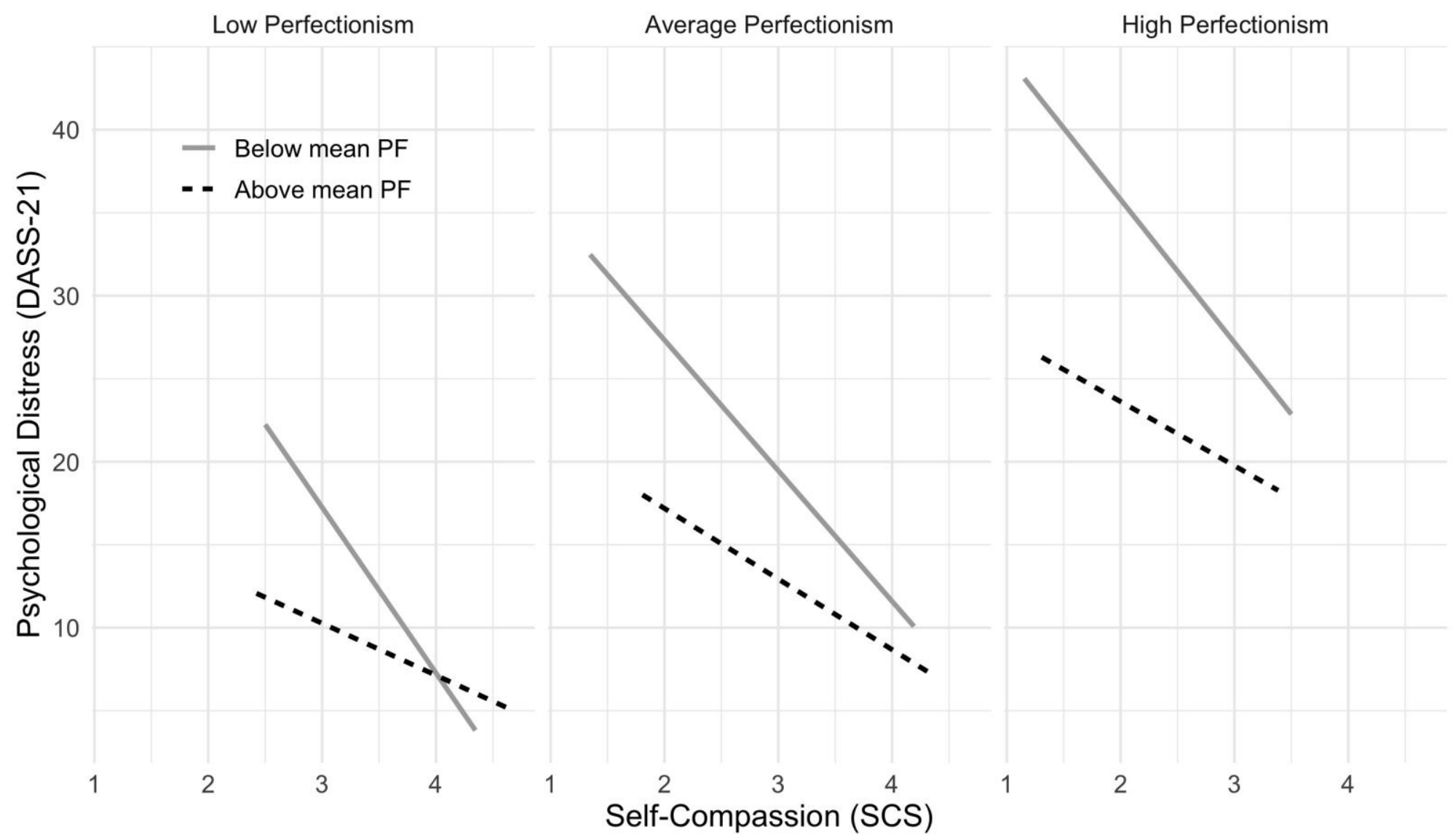

Figure 4. Plot of best-fitting lines showing the non-significant three-way interaction effect of group, self-compassion, and psychological flexibility on psychological distress. DASS-21 = Depression Anxiety Stress Scales; PF = psychological flexibility (as measured by the CompACT [Comprehensive Assessment of ACT Processes]); SCS = Self-Compassion Scale. 